\section{Revelación y teología de las religiones: J. Dupuis y A. Torres Queiruga en diálogo*}

\author{
Luis Guillermo Restrepo Jaramillo **
}

RECIBIDO: 17-04-15 - APROBADO: 06-07-15

RESUMEN: ¿Es posible la legitimación del pluralismo religioso desde la revelación cristiana? Entre los muchos teólogos contemporáneos que se han ocupado de la cuestión, proponemos un diálogo entre J. Dupuis y A. Torres Queiruga, que permite afirmar que la revelación por hechos y palabras, como la presenta la Dei Verbum, supone una acción salvífica de Dios en las religiones del mundo. El pluralismo religioso, entonces, no es extraño al plan divino de salvación.

Palabras clave: Revelación, teología de las religiones, diálogo interreligioso, pluralismo religioso.

PARA CITAR ESTE ARTÍCULO:

Restrepo Jaramillo, Luis Guillermo. "Revelación y teología de las religiones: J. Dupuis y A. Torres Queiruga en diálogo." Theologica Xaveriana 180 (2015): 447-470. http://dx.doi.org/10.11144/javeriana.tx65-180.rtr
Revelation and Theology of Religions: J. Dupuis and A. Torres Queiruga in Dialogue

Aвstract: Is it possible to legitimate religious pluralism from the perspective of Christian revelation? Amongst the group of contemporary theologians who have studied this question, we propose a dialogue between J. Dupuis and A. Torres Queiruga to assert that the revelation by deeds and words -as it is shown by $D e i$ Verbum-implies a salvific action of God in the religions of the world. Thus, religious pluralism is not something odd to the divine plan of salvation.

KeY wORDS: Revelation, theology of religions, interreligious dialogue, religious pluralism.

Revelação e teologia das religiões: J. Dupuis e A. Torres Queiruga em diálogo

Resumo: É possível legitimar o pluralismo religioso partindo da revelação cristâ? Entre os muitos teólogos contemporâneos que se ocuparam do assunto, propomos um diálogo entre J. Dupuis e A. Torres Queiruga, que permite afirmar que a revelação por fatos e palavras como mostra a Dei Verbum, supóe uma ação salvante de Deus nas religiões do mundo. O pluralismo religioso, então, não é estranho ao plano divino de salvaçáo.

Palavras chave: Revelação, teologia das religióes, diálogo inter-religioso, pluralismo religioso.

* El presente artículo deriva de la tesis doctoral en Teología presentada en la Pontificia Universidad Javeriana, Bogotá.

** Doctor en Teología, Pontificia Universidad Javeriana (Bogotá). Docente investigador de la Universidad Católica de Manizales y decano (e) de la Facultad de Educación de la misma universidad. Correo electrónico: lgrestrepo@ucm.edu.co 


\section{Introducción}

El tema de este artículo es de actualidad, pero es tan antiguo como el cristianismo. A fin de cuentas, la comunidad apostólica tuvo que situarse frente a la fe de Israel y, además, demarca su relación con el mundo griego y el llamado "paganismo" de aquella época (Hch 17,19-34). Sin embargo, en la realidad del mundo contemporáneo, mundo plural y globalizado, aparece el tema del encuentro con las religiones no cristianas y las inquietudes que ello comporta. ${ }^{1}$

Como podremos ver, el tema aquí no es simplemente la teología de las religiones como problemática general. El interés de este artículo se centra en una de las preguntas de la teología del pluralismo religioso o de la teología de las religiones ${ }^{2}$, que es la pregunta por la revelación divina, y si esta puede ser la clave -o llave- para su profundización. Debemos aclarar estas categorías que guían nuestro estudio.

La revelación es, ante todo, la posibilidad de la automanifestación divina al hombre, que lleva a este a descubrir como aquella lo puede iluminar y salvar, y cómo lo quiere atraer con amor, por medio de un plan salvífico. Esta revelación se da en y por la historia en la cual Dios se revela y salva. Revelación y salvación van así de la mano. Ya hemos escuchado en el Nuevo Testamento las siguientes palabras:

Muchas veces y de muchas maneras habló Dios en el pasado a nuestros padres por medio de los profetas. En estos últimos tiempos nos ha hablado por medio del Hijo a quien instituyó heredero de todo, por quien también hizo el universo. (Hb 1,1-2).

Sabemos que el escritor bíblico quería señalar de modo indiscutible cómo el acontecimiento Jesucristo superaba de manera incomparable las demás manifestaciones de Dios hasta el momento. No obstante, esa expresión de "muchas veces y de muchas maneras" invita a pensar que la revelación divina puede ir más allá de la historia bíblica ${ }^{3}$, es decir, está inserta en la historia. ${ }^{4}$

\footnotetext{
${ }^{1}$ Dupuis, Jesucristo al encuentro de las religiones, 12-13, Knitter, Introducción a las teologías de las religiones, 13-64.

${ }^{2}$ No todos los autores están de acuerdo en el nombre de teología de las religiones. Por ello, J. Dupuis pone su acento en una teología del pluralismo religioso, lo que centra su atención no en el diálogo con las otras religiones, sino en el sentido de la pluralidad religiosa en el plan salvífico de Dios, al tratar de entender qué lugar les da Dios a esas otras tradiciones religiosas en su orquestado plan salvífico. Véase a Teixeira, Teologia de las religiones. Una visión panorámica, 54-55.

${ }^{3}$ Dupuis, Hacia una teología cristiana del pluralismo religioso, 348.

${ }^{4}$ Para mayor profundización de esta temática, véase Parra, Textos, contextos y pretextos. Teología fundamental, $87-111$.
} 
Allí subrayamos que la automanifestación de Dios en la historia tiene lugar inseparablemente bajo la doble forma de palabras y obras; está formada al mismo tiempo, necesariamente, de revelación y de salvación: Dios se dice a sí mismo dándose a sí mismo; se comparte a sí mismo pronunciándose a sí mismo. Así pues, afirmar que toda la historia es historia de salvación implica por ello mismo la universalidad de la revelación. Obras y palabras, acontecimientos y profecía: ambas cosas van de la mano. ${ }^{5}$

Ahora, vale la pena preguntarnos qué entendemos por teología de las religiones. Es necesario decir que no es simplemente una teología del genitivo ${ }^{6}$, pues busca mucho más; quiere aclarar una pregunta nueva: ¿cuál es significado y el valor salvífico de las religiones en cuanto tales? Tal pregunta se puede realizar desde cada religión, para dar origen a una teología de las religiones desde los diversos puntos de vista de cada una de ellas. Esto lleva a descubrir el encuentro entre creyentes de distintas religiones, en este mundo plural, como un verdadero lugar teológico. ${ }^{7}$

Sin embargo, debemos reconocer que esta pregunta es nueva para la teología sistemática y que es tarea de este siglo lograr lo que proponía Paul Tillich: “...escribir una teología sistemática orientada hacia la historia de las religiones y en diálogo con ellas." ${ }^{8}$ Podemos decir, entonces, que la teología cristiana de las religiones es la disciplina que pretende dar solución a los problemas que aparecen ante nosotros, por vivir en un mundo plural.

En el marco de estos conceptos queremos proponer como hipótesis que la revelación puede ser una clave oportuna para la elaboración de una reflexión teológica de las religiones; clave que abre posibilidades de comprensión e interpretación para la sistematización de la pluralidad religiosa en el plan divino.

Nos proponemos realizar este camino mirando dos posiciones teológicas contemporáneas y reconociendo desde el principio que la Iglesia no se ha manifestado de manera definitiva sobre este tema, que ella misma considera novedoso ${ }^{9}$ y, por lo mismo, necesitado de investigación teológica más profunda.

${ }^{5}$ Dupuis, Hacia una teología cristiana del pluralismo religioso, 349.

${ }^{6}$ Dupuis, "Méthode théologique et theologies locales", 61-74.

${ }^{7}$ Sánchez Hernández, "Inreligionación y pluralismo: una perspectiva teológica para el encuentro interreligioso", 54.

${ }^{8}$ Gibellini, La teología del siglo XX, 552.

${ }^{9}$ Congregación para la Doctrina de la Fe, "Notificación a propósito de libro del Rvdo. P. Jaques Dupuis, S.J., Hacia una teología cristiana del pluralismo religioso", Vatican, http://www.vatican.va/roman_curia/ congregations/cfaith/documents/rc_con_cfaith_doc_20010124_dupuis_sp.html (consultado el 14 de abril de 2015). 
Diferentes teólogos podrían ser estudiados -H. Küng, R. Panikkar, P. Knitter, J. Hicks, y muchos otros-, pero optamos por dos teólogos de frontera entre el inclusivismo y el pluralismo. ${ }^{10}$

En primer lugar, nos proponemos presentar la propuesta de J. Dupuis ${ }^{11}$ sobre este punto. Si el inicio de la teología de las religiones descubre su fundamento en teólogos como K. Rahner y su teoría del cristianismo anónimo, en Dupuis se puede ver la evolución de la temática y las propuestas que pueden ir más allá de lo tratado por quienes lo precedieron. Además, su posición sobre el tema de la revelación aparece con claridad en sus libros, en los que es tratado con seriedad y agudeza, e intenta superar las tensiones que impiden un verdadero diálogo interreligioso, que debe darse en un campo más neutro.

En segundo lugar veremos las propuestas de A. Torres Queiruga, teólogo contemporáneo, claro en su visión de la teología de la revelación y en las propuestas para repensarla, quien sabe hacer una buena presentación de la fenomenología del problema y ofrece así propuestas que pueden dar un avance a la ciencia sobre este punto, en el que incluso aporta nuevas categorías a la reflexión.

Muchas preguntas podríamos hacer sobre este punto de la revelación y la teología de las religiones: jes tan extensa la revelación divina como la misma historia del mundo? ¿Es posible pensar que Dios no dejó de dar testimonio de sí mismo, no solo en sus obras, sino en su autocomunicación a los hombres? ¿Es posible decir que Dios se ha manifestado a los hombres por medio de los profetas de otras tradiciones religiosas, antes y después de Jesucristo, que es la plenitud de la revelación de Dios? Si Jesucristo es la plenitud de la revelación divina ¿ha quedado abrogado todo lo demás? ¿Para qué requería de otras manifestaciones? ¿Es cerrada dicha revelación o se puede imaginar como un proceso que aun continúa dentro y fuera de la tradición cristiana?

Estas preguntas son fundamentales porque, en la automanifestación de Dios en la historia, se da la salvación; por consiguiente, cualquier inquietud sobre la salvación de los hombres en otras religiones es también la pregunta por la revelación de Dios en ellas.

\footnotetext{
${ }^{10}$ Una visión general de los teólogos que han estudiado el tema en: Knitter, Introducción a las teologías de las religiones, 443. Un ejemplo de estudio a partir de Panikkar: Pérez Prieto, La buisqueda de la armonía en la diversidad, 1-177.

${ }^{11}$ En estos dos artículos Dupuis hace frente a las críticas a su obra en el ámbito de lengua inglesa y de lengua italiana. Véase Dupuis, "La teología del pluralismo religioso revisitata", 669-693; idem, "'The Truth Will Make You Free. The Theology of Religious Pluralism Revisited”, 211-263.
} 
Centraremos nuestra atención en la posibilidad de la revelación en las tradiciones no cristianas y en cómo esta puede ser clave de comprensión del pluralismo religioso como hecho que interroga a la teología. Al tener claro que la respuesta que se busca será dada desde el cristianismo y no desde otras tradiciones religiosas, el interés fundamental es una respuesta desde nuestra fe.

Es imposible tratar todas las posturas que sobre este tema se ven, en la actualidad, en la teología de las religiones. ${ }^{12}$ Por ello, es necesario centrar la atención en la postura de dos autores contemporáneos que han tratado el tema y que pueden ayudar a dar elementos de solución.

\section{La postura de J. Dupuis: propuesta desde la teología cristiana del pluralismo religioso}

El padre J. Dupuis desarrolló una propuesta sobre la teología de las religiones en la cual presentó un interesante desarrollo sobre la revelación. Su visión tiene como punto de partida una cristología trinitaria y pneumatológica ${ }^{13}$, en la que el Reino de Dios $^{14}$ tiene un lugar central y deben entrar las religiones de algún modo en el plan salvífico universal de Dios en Jesucristo. ${ }^{15}$ Incluso esta postura es calificada como "más allá del cumplimiento"16, o sea, que al tratar de mantenerse en la ortodoxia es propositiva y da elementos que van más allá de la teoría del cumplimiento, como es sostenida hasta hoy. ${ }^{17}$

\footnotetext{
${ }^{12}$ Para la revisión de los diversos modelos puede verse a Knitter, Introducción a las teologías de las religiones, 64 -443. Más brevemente, puede verse Pérez Prieto, La búsqueda de la armonía en la diversidad. El diálogo ecuménico e interreligioso desde el Concilio Vaticano II, 75-78.

${ }^{13}$ Dupuis, "Le Verbe de Dieu, Jésus Christ et les religions du monde", 529-546.

${ }^{14}$ Idem, "The Kingdom of God and World Religions", 530-540; idem, "Apostolic Exhortation Evangelii Nuntiandi of Pope Paul VI", 218-230; idem, "World religions in God's Salvific Design in John Paul II's Discourse to the Roman Curia", 29-41.

${ }^{15}$ Idem, "Le dialogue interreligieux a l'heure du pluralisme", 544-563 ; idem, "Le pluralisme religieux dans le plan divin de salut", 484-505.

${ }^{16}$ Knitter, Introducción a las teologías de las religiones, 187.

${ }^{17}$ La notificación de la Congregación para la Doctrina de la Fe del 24 de enero de 2001 versa sobre los posibles errores a que puede conducir la obra Hacia una teología cristiana del pluralismo religioso, sin condenar al autor, del cual reconoce su honesta búsqueda teológica y su deseo de permanecer fiel a la doctrina de la Iglesia Católica. Sin embargo pone uno de sus énfasis en el tema sobre la unicidad y plenitud de la revelación cristiana. Para la mejor comprensión de este debate teológico se puede consultar a O'Collins, "Jacques Dupuis. His person and Work", 18- 29; idem, "Jacques Dupuis: The Ongoing Debate”, 632-654.
} 
Para Dupuis, la revelación de Dios y la salvación deben ir íntimamente relacionadas. La concomitancia de hechos y palabras divinas lleva a la búsqueda sincera de un discurso divino en las religiones no bíblicas, lo cual incluye a todas en el ámbito de la historia de la salvación. ${ }^{18}$ Dios ha hablado a toda la humanidad, porque ha ofrecido la salvación a todos. La revelación, pues, debe ser universal, igual que es el ofrecimiento de la salvación. ${ }^{19}$ La historia está marcada por la voluntad salvífica universal de Dios (1Tm 2,4).

$\mathrm{Al}$ afirmar lo anterior, no se quiere negar que la comprensión de conceptos como revelación y salvación sean muy diferentes en el marco de las diversas religiones, pero esto no puede negarle al cristiano la posibilidad de elaborar una interpretación de las otras religiones desde el punto de vista de su propia fe. ${ }^{20}$

Dupuis recurre a los modelos de la revelación divina propuestos por Dulles ${ }^{21}$ en su obra sobre el tema, para considerar cuáles de estos modelos se pueden ajustar a las otras tradiciones religiosas, que son los más adecuados para entender la revelación divina en ellas. Los cinco modelos son los siguientes: revelación como doctrina, revelación como historia, revelación como experiencia interior, revelación como presencia dialéctica y revelación como nueva conciencia. ${ }^{22}$ Es de anotar que el mismo Dulles dice: "Por razones que he expuesto en Models of Revelation, ninguna de estas opciones parecía plenamente satisfactoria." ${ }^{23}$

De los diversos modelos se puede decir que, en el primero, hay una visón rígida de distinción entre natural y sobrenatural, que da paso a la visión exclusivista; en el segundo se da frecuentemente una visión estrecha de la historia de la salvación, según la cual en la historia en general es imposible la revelación; en el cuarto modelo se establece un abismo entre el sujeto y el objeto de la revelación. Los otros dos modelos, el tercero y el quinto, que son más abiertos a lo simbólico, pueden ver con mayor fácilidad la presencia de la revelación en las otras religiones.

${ }^{18}$ Rahner, "Profane History and Salvation History", 4026-4033. Muchos estudios se han realizado sobre la historia y la teología; sin embargo, Dupuis centra su atención en profundizar la visión de Rahner, complementándola.

${ }^{19}$ Dupuis, Hacia una teología cristiana del pluralismo religioso, 349-350.

${ }^{20}$ Ibid., 350-351.

${ }^{21}$ Dulles, Models of Revelation, 120-122.

${ }^{22}$ Dupuis, Hacia una teología cristiana del pluralismo religioso, 352-353.

${ }^{23}$ Dulles, El oficio de la teología, 66. 
Hablando de la revelación como "experiencia interior", Dulles se refiere a $\mathrm{K}$. Rahner para sostener que la revelación contiene un movimiento o dimensión trascendente, que significa "la autocomunicación de Dios en la gracia divinizadora, en la medida en que tal gracia modifica la perspectiva con que miramos el mundo". "La revelación", afirma Rahner, "no es posible [...] sin la presencia de lo que se puede llamar la mística como expresión de la gracia." Tal gracia iluminadora puede ser llamada revelación ya antes de la aceptación de un mensaje específico divinamente revelado; será "tematizada" en las doctrinas, que reflejan verdades divinas y son trasmitidas por las tradiciones religiosas. Así pues, no solo el cristianismo, sino también las otras tradiciones religiosas pueden dar testimonio, en diverso grado, de una autorrevelación de Dios. ${ }^{24}$

El modelo de la nueva conciencia también puede ayudar a ver la revelación en las otras tradiciones religiosas, en la medida en que un individuo o una comunidad, al contar con la presencia de Dios, tienen una experiencia fundante en lo divino, lo cual hace posible encontrar en ellos la revelación.

Lo anterior no relativiza la revelación, ni a Jesucristo, que sería siempre la definitiva e irrevocable autocomunicación divina. ${ }^{25}$ Podemos señalar que el peligro de estos dos modelos es el de relativizar la persona Jesús y su obra reveladora.

Dupuis centra su atención en la estructura trinitaria de la revelación. Porque cualquier autocomunicación de Dios es siempre una automanifestación del Dios de Jesucristo que se revela, es decir, un encuentro con el Dios trinitario. Así como es el Dios padre, Hijo y Espíritu Santo el que marca la historia de la salvación, del mismo modo esa estructura trinitaria se verá en la revelación divina: “...cada vez que Dios ha hablado en la historia humana, lo ha hecho por su Palabra, en su Espíritu”. ${ }^{26}$

En el prólogo de San Juan queda claro que Dios habla con su Palabra y que así ilumina a todo hombre, viviendo en este mundo (Jn 1,1-3.9). Este texto fue tomado en cuenta por el Vaticano II para decir que las otras tradiciones religiosas "no pocas veces reflejan un destello de aquella verdad que ilumina a todos los hombres". ${ }^{27}$

Por otra parte, la doctrina posconciliar ha reconocido abiertamente la actividad del Espíritu Santo, no solo en la vida de los miembros de las otras religiones, sino también en sus tradiciones.

\footnotetext{
${ }^{24}$ Dupuis, Hacia una teología cristiana del pluralismo religioso, 354.

25 Ibid., 354.

${ }^{26}$ Ibid., 359.

${ }^{27}$ Concilio Vaticano II, "Declaración Nostra aetate sobre las relaciones de la Iglesia con las religiones no cristianas" 2.
} 
La presencia activa del Espíritu es universal. Anticipa el acontecimiento de Jesucristo y, después de este acontecimiento, se extiende más allá de los confines de la Iglesia. El Espíritu se difunde en todo el mundo, vivificando todas las cosas. La revelación cósmica es asumida ella misma en esta transformación. ${ }^{28}$

Es siempre en el Espíritu donde es posible estar juntos Dios y los hombres, pues la Palabra se encarna y es el Espíritu quien nos hace posible acceder a él. En su Espíritu, Dios se nos hace presente, de tal modo que el hombre puede hablar de un encuentro personal desde lo profundo de su corazón.

Por tanto, podemos decir que el Espíritu Santo preside el destino divino de la humanidad, en el sentido de que cada alianza divina alcanza a la humanidad en el Espíritu. En los diversos periodos de la historia de la salvación, como en la historia personal de la salvación de los seres humanos, actúa, revelando y manifestando a Dios, el mismo Espíritu. ${ }^{29}$

Se llega necesariamente a la plenitud de la revelación en Jesucristo. ${ }^{30}$ La palabra decisiva de Dios al mundo es el Hijo encarnado. Incluso se dice que Jesucristo lleva a plenitud la revelación. ${ }^{31}$

Dupuis presenta el hecho de que tal plenitud no es la palabra escrita del Nuevo Testamento; esta es la memoria auténtica de dicha revelación y se convierte en la norma normans para la fe de la Iglesia de todos los tiempos. En realidad, Jesucristo, personalmente, es la plenitud de la revelación, si se piensa cualitativa y no cuantitativamente. Por su identidad personal de Hijo de Dios, ya se le ve como el culmen de la Palabra revelada.

Si la revelación divina alcanza su plenitud cualitativa en Jesús, es porque ninguna revelación del misterio de Dios puede igualar la profundidad de lo que sucedió cuando el Hijo de Dios encarnado vivió en clave humana, en una conciencia humana, su propia identidad como el Hijo de Dios. Esto es lo que sucedió en Jesucristo, y esto es lo que está en el origen de la revelación divina que nos entrega. ${ }^{32}$

\footnotetext{
${ }^{28}$ Dupuis, Hacia una teología cristiana del pluralismo religioso, 361.

${ }^{29}$ Ibid., 362.

${ }^{30}$ Idem, "Le débat christologique dans le contexte du pluralisme religieux", 853-863 ; idem, Introducción a la cristología, 49-53. El debate cristológico provocado por el contexto actual no es el centro de nuestro artículo, pero no debe ser olvidado en el trasfondo del tema.

${ }^{31}$ Concilio Vaticano II, “Constitución dogmática Dei Verbum sobre la divina revelación” 4.

${ }^{32}$ Dupuis, Hacia una teología cristiana del pluralismo religioso, 369.
} 
Sin embargo, Dupuis afirma que esta revelación es relativa, pues la conciencia humana de Jesús, aunque es la del Hijo, sigue siendo humana, y por lo mismo es conciencia limitada. Por ello, ni siquiera la conciencia humana del Hijo de Dios puede agotar todo el misterio divino, sin olvidar que es gracias a esta experiencia humana de Jesús -la de ser el Hijo de Dios- lo que permite traducir en lenguaje humano el misterio divino que reveló. ${ }^{33}$

La plenitud cualitativa -o, digamos, la intensidad- de revelación en Jesucristo no es un obstáculo, ni siquiera después del acontecimiento histórico, para una autorrevelación divina permanente a través de los profetas y los sabios de otras tradiciones religiosas, como, por ejemplo, a través del profeta Mahoma. Esa revelación sucedió y continúa sucediendo en la historia. Pero ninguna revelación puede superar o igualar, antes o después de Cristo, la que se nos concedió en él, el Hijo divino encarnado. ${ }^{34}$

No se quiere renunciar al hecho de que la plenitud de la revelación en Jesucristo es insuperable, pero esto no niega que Dios sigue hablando a los hombres en el mundo actual. Como afirmaba el mismo San Agustín, hay profetas en la Iglesia y también es posible descubrirlos en otras tradiciones religiosas. Así, en la Iglesia sigue realizándose la revelación en Jesucristo, y fuera de ella puede ser sugerida o vista mediante rostros incompletos de él, como auténticos presentimientos del misterio revelado en Jesucristo. ${ }^{35}$

Por último, la propuesta de Dupuis llega a la idea de la revelación como diferenciada y complementaria. Básicamente piensa que la Palabra decisiva no excluye otras palabras: más bien las supone. Dicha Palabra divina se haría presente no solo en el Antiguo Testamento y el Nuevo Testamento, que son Palabra de Dios, sino también en los escritos dirigidos a las naciones.

Esta propuesta la realiza distinguiendo periodos: (1) uno en el cual se contendrían palabras secretas, que incluso estarían presentes en los escritos de otras religiones y que serían indicios; (2) uno en el cual Dios habla a Israel de modo oficial y del cual es testimonio escrito el Antiguo Testamento; y (3) uno último en el cual Dios da su Palabra al mundo, el Verbo encarnado, que sería del cual el Nuevo Testamento da testimonio. Hacia el último periodo estarían dirigidos los dos primeros, aunque en grado diverso. ${ }^{36}$

\footnotetext{
${ }^{33}$ Ibid., 369.

${ }^{34}$ Ibid., 370.

${ }^{35}$ Idem, El cristianismo y las religiones. Del desencuentro al diálogo, 189-190.

${ }^{36}$ Idem, "Dialogue and Proclamation: A Theological Commentary", 119-158. En este artículo ya comentaba Dupuis esta relación y posible desarrollo.
} 
De lo anterior brotaría la pregunta de qué quieren decir las expresiones Palabra de Dios, inspiración y escrituras sagradas. Según Dupuis, estos serían términos análogos que se aplicarían a cada uno de los periodos de esa revelación progresiva y diferenciada. ${ }^{37}$

La revelación es progresiva y diferenciada. Se podría incluso decir -sin que ello vaya en detrimento del carácter decisivo del acontecimiento Cristo- que entre la revelación dentro de la tradición judeo-cristiana y la exterior a ella existe una verdadera complementariedad. Y, de manera equivalente, se podría decir que entre los libros sagrados de las otras tradiciones religiosas y el corpus bíblico se puede encontrar una complementariedad semejante. "La verdad tiene dos ojos", como se ha recordado anteriormente; y el mismo Dios que habló en la historia por medio de sus profetas fue el que habló también a los videntes en el secreto de sus corazones. Toda verdad viene del Dios que es Verdad y debe ser honrada como tal, cualquiera que sea el canal por el que llega a nosotros. ${ }^{38}$

Evidentemente es necesario un discernimiento que permita separar la verdad divina de lo que no lo es y aprender a descubrir lo que nos ayude a comprender más profundamente lo que de modo pleno y claro nos fue revelado en Cristo. ${ }^{39} \mathrm{Sin}$ embargo, seguramente, la cercanía a las otras tradiciones religiosas puede ayudar a esta más profunda comprensión de lo que ya nos fue manifestado claramente y que contemplamos siempre en Jesucristo.

Esto no quiere decir que la revelación no sea plena y perfecta, sino que la verdad en el Espíritu, presente así sea como "semillas del verbo" 40 en otras religiones, puede ayudar a nuestra profundización del misterio divino manifestado en Jesucristo. La complementariedad no negaría la plenitud y perfección de la revelación en Cristo; al contrario, simplemente nos ayudaría a profundizar su conocimiento y comprensión.

Para Dupuis -según lo que hemos visto-, parece posible la revelación en las otras tradiciones religiosas, con las peculiares distinciones que establece en su obra.

\footnotetext{
${ }^{37}$ Idem, Hacia una teología cristiana del pluralismo religioso, 370-372.

${ }^{38}$ Ibid., 372-373.

${ }^{39}$ Meza, "De la cristología a la cristofanía. Dupuis y Panikkar en diálogo”, 115-136. En este artículo puede verse la perspectiva cristológica de Dupuis en diálogo con la cristofanía de Panikkar. Así se puede tener una profundización desde la cristología para este tema.

${ }^{40}$ Este término de San Justino aparece varias veces citado por el Vaticano II y por la mayoría de autores que tratan este tema, pero merecería estudio aparte la comprensión que ha tenido la expresión en la teología cristiana desde San Justino hasta hoy.
} 


\section{La postura de A. Torres Queiruga: propuesta desde la mayéutica histórica}

La posición sobre la revelación de A. Torres Queiruga fortalece los dos polos de la autocomunicación divina. Hay un Dios que se da a conocer y un hombre que "cae en la cuenta" de tal comunicación.

Es necesario tener presente que el acto de la revelación no es una mera actividad del hombre, sin más, sino un acto comunicativo de Dios. ${ }^{41}$ Dice Torres Queiruga:

...Dios no necesita romper milagrosamente e intervencionistamente la justa autonomía del sujeto para poder anunciarse en su inmanencia. La razón está en que no se trata de que "venga desde fuera", con su inspiración a un receptor separado y lejano. Más bien se trata de lo contrario: Dios está ya siempre dentro, sustentando, promoviendo e iluminando la misma subjetividad, que por eso le busca y puede descubrirlo. En definitiva, la revelación consiste en "caer en la cuenta" del Dios que, como origen fundante, está ya dentro, habitando nuestro ser y tratando de manifestársenos. ${ }^{42}$

Para su comprensión de la revelación, Torres Queiruga toma la categoría mayéutica histórica con la cual logra entrelazar al Dios que se manifiesta con aquel a quien se le manifiesta.

De esta manera logra una apertura del concepto desde la realidad antropológica en la cual el hombre -en su realidad existencial trascendente ${ }^{43} y$ desde su propio contexto- puede descubrir al Dios que se revela en el mundo.

Así, en el hecho de la revelación, el ser humano se redescubre a sí mismo, porque conoce, encuentra y afirma su propio ser. ${ }^{44}$ Por eso podemos decir que su intuición de "caer en la cuenta” es la que lleva a la propuesta de la categoría de mayéutica histórica.

${ }^{41}$ Torres Queiruga, “Aclaraciones sobre una notificación”, 159-168. Véase Conferencia Episcopal Española, "Notificación sobre algunas obras del prof. Andrés Torres Queiruga”, párrafos 7-16.

${ }^{42}$ Torres Queiruga, Fin del cristianismo premoderno. Retos hacia un nuevo horizonte, 43.

${ }^{43}$ La categoría trascendental de K. Rahner no es del agrado de este autor, pero su contenido sí; aquí se vería referencia al existencial sobrenatural y a las posibilidades que dejó abiertas el método antropológico trascendental.

${ }^{44}$ Torres Queiruga, Repensar la revelación. La revelación divina en la realización humana, 123-183. 
En todo esto la función de la palabra -o de la palabra-obra, palabra-signo- es claramente mayéutica: ni llevar fuera de sí, ni hablar de cosas extrañas; al contrario, devolver al ser humano a su más radical autenticidad, despertándolo del sueño/ensoñación de las apariencias (cfr. Rm 13,11) Y aclarándole la realidad verdadera que es y está siempre llamado a ser desde su estar fundado en la acción creadora y salvadora de Dios. Esta, previa a toda noticia y a toda opción, estaba ya modelando la intimidad de todo hombre y mujer, llamándolos a su descubrimiento e invitándolos a la aceptación: "Cristo, el vencedor, el kyrios que reina sobre todos los pueblos, está ya siempre allí a donde el predicador llega." La palabra hace, con toda propiedad, de "partera" que trae esta presencia a la luz de la conciencia y a la visibilidad de la historia. ${ }^{45}$

Esta categoría tiene un aspecto histórico pues, aunque el Dios que se manifiesta es eterno, lo hace en el contexto humano, que es histórico y evolutivo. La revelación divina solo se hace concreta en el marco humano, que lleva al hombre a su realización. Por ello dice Torres Queiruga que "la revelación, incluso una vez propuesta, sigue siendo llamada y desafío" .46 Simplemente la revelación nos lleva a la verdad y a descubrirla en nosotros, venciendo todo lo que nos impide descubrirla plenamente y hacerla vida. Así, la verdad que Dios nos revela, es nuestra propia verdad, descubierta en tal acontecer histórico.

Dios está realmente presente a todos los seres humanos; estos, en su experiencia religiosa, captan su presencia como revelación activa y salvadora; entre ellos hay un pueblo, el de Israel, que vive y expresa de un modo específico esa revelación, iniciando así la historia santa que aparece recogida en la Biblia. ${ }^{47}$

En este mismo contexto se nos hace necesario afirmar el punto fundamental de nuestra fe, que no es otro que la plenitud y definitividad de la revelación de Dios en Jesucristo.

En la lógica de Torres Queiruga, se hace necesario redescubrir a Jesús, el Cristo, como el que elimina toda ambigüedad de la vivencia de Dios en el proceso revelatorio y la enriquece plenamente con su apertura total a la vida, en la encarnación, muerte y resurrección. Además, es necesario afirmar que solo en este acto culminante aparece la presencia salvadora de Dios a todos los pueblos, no como algo totalmente novedoso, sino como eso que buscaban, sin ver claramente. ${ }^{48}$

\footnotetext{
${ }^{45}$ Ibid., 181.

${ }^{46}$ Ibid., 181. En otras obras, Torres Queiruga ha hecho afirmaciones similares. Véase Diálogo de las religiones y autocomprensión cristiana, 51.

${ }^{47}$ Torres Queiruga, Repensar la revelación, 196.

${ }^{48}$ Ibid., 197.
} 
Cuando se habla de la plenitud de la revelación en Cristo, es necesario explicarla. Para Torres Queiruga, dicha plenitud es intensiva y extensiva. La plenitud intensiva se refiere al hecho mismo de que, solo en Cristo, Dios puede revelar plenamente su presencia al hombre, pero además Cristo es el modelo de respuesta humana a ese Dios que se revela.

Así se hace real el amor salvador de Dios al hombre y se posibilita una acogida sin deformaciones causadas por el pecado. Más aun, dicha acogida es plena porque toda la historia la recapitula Cristo, quien hace suyo todo el proceso revelador hasta el momento y abre, para los demás hombres de todos los tiempos, el acceso a esa plenitud. "Posibilidad real y actual, es decir, vivible y experimentable por cada nueva generación." ${ }^{9}$

Sin embargo, esta plenitud también es apertura, y apertura histórica, pues -como presencia del Resucitado en la humanidad- es futuro siempre abierto a la construcción del proyecto, lo cual lo hace permanecer siempre como promesa escatológica. La plenitud intensiva de la revelación en Jesucristo es, pues, recapitulación del pasado y apertura a la construcción de futuro.

Así, nuestra memoria o recuerdo se convierte en oportunidad constructora y realizadora de esta historia salvífica en la cual se realiza la revelación, con el sentido dinámico que nos hace ver, en cada momento histórico, una relectura de la revelación de Cristo, actualizándola y universalizándola. ${ }^{50}$

Igualmente, la capacidad de universalización, por la que todo Israel se apropiaba de lo acontecido a cualquier individuo o grupo de su historia, alcanza en Cristo el paroxismo: "se derrumba el muro" (Ef 2,14), se eliminan las diferencias de varón o mujer, esclavo o libre, judío o griego (Ga 3,28). Ahora no es ya solo Israel quien puede apropiarse la revelación, sino el mundo entero: todas las gentes, todas las épocas y todas las culturas reciben la posibilidad de hacerse discípulos (Mt 28,20), de entrar en posesión de la inconmensurable riqueza de lo manifestado por Dios en Cristo" $($ Ef 3,8$) .^{51}$

No obstante, de inmediato nace la pregunta sobre esta pretensión de universalidad: ¿`No es acaso una manifestación del más inocente etnocentrismo? Torres Queiruga responde diciendo:

\footnotetext{
${ }^{49}$ Ibid., 318.

${ }^{50}$ Ibid., 278-320.

${ }^{51}$ Ibid., 320.
} 
Dado que procede por "emergencia" e intensificación del fondo común que es la presencia reveladora de Dios a todos los hombres, escapa a la limitación del primero, del excluyente. La universalidad cristiana no constituye un núcleo aislado, que solo a medida que se extiende va alcanzando lo que está afuera y le es externo y ajeno. Al contrario, parte desde dentro de la misma experiencia de todos, sin negar todo lo que también ellos han descubierto a su modo en su conciencia, en su cultura y sobre todo en sus religiones. ${ }^{52}$

La respuesta del autor nos invita entonces a comprender la universalidad por "emergencia" e intensificación. Con ello no se negaría la universalidad y no se dejaría de valorar la realidad y experiencia ajena. Todas las culturas y religiones tienen su propia experiencia, en la cual debe darse la universalidad de la revelación, sin perder nada de lo verdadero y bueno.

Así se ve que la pretensión de universalidad no es un añadido, sino nace del carácter insuperable y universal de la revelación de Cristo, el Dios hecho hombre.

Algo así lleva a experimentar que Cristo es el don de Dios para todos, que quiere ofrecerse a los demás: no para violar su libertad, ni para imponerse, sino para ofrecerse, como dice Torres Queiruga: "Se trata -repitámoslo una vez más- de un ofrecimiento mayéutico, que no llama fuera de sí, sino al reconocimiento pleno de la propia realidad desde Dios." ${ }^{53}$

Ahora aparece, como consecuencia de esta universalidad intensiva, una universalidad extensiva que lleva a la reflexión sobre el encuentro con las religiones y las culturas. ${ }^{54}$

Para ello Torres de Queiruga propone evitar dos tentaciones: ver el cristianismo como el único lugar posible para la presencia de Dios y, en consecuencia, ver la elección divina como elemento exclusivista que lleva al rechazo de los demás como falsos. Porque como todos los hombres y mujeres están inmersos constitutivamente en su relación con Dios y las religiones tematizan tal relación real, "todas las religiones son, en principio, verdaderas". 55

\footnotetext{
52 Ibid., 349.

${ }^{53}$ Ibid., 386.

${ }^{54}$ Es de anotar que Torres Queiruga ve este tema más desde la teología de las religiones y la preocupación sincera por el diálogo humilde, equilibrado y constructivo (Torres Queiruga, Diálogo de las religiones y autocomprensión cristiana, 12-29). Véase la propuesta de Claude Geffré centrada más en el diálogo mismo que en otros aspectos, referida a un ecumenismo planetario (Geffré, Credere e interpretare. La svolta ermeneutica della teologia, 115-124).
}

55 Torres Queiruga, Repensar la revelación, 390. 
De lo que se trata es, pues, de ver el "tipo de verdad" que, en esa difícil y oscura pugna por captar la irradiación amorosa del misterio, alcanza cada religión, La única dialéctica auténtica es entonces - iy con cuanta cautela y cuántas precisiones será preciso proceder!- la de verdadero/más verdadero o, como en otro contexto decía con referencia a Eberhard Jüngel -y evitando todo juicio moralista-, la de bueno/mejor (no la de malo/bueno) (cfr. Cap. VI, 1.2). Y esto, sabiendo que, en cuanto a su realización dentro de las limitaciones de una comunidad histórica, verdadero/más verdadero y bueno/mejor no pueden ser tomadas jamás en sentido absoluto; la posibilidad de un "mejor saldo de conjunto" no debe ocultar la evidencia de que todo progreso humano comporta siempre una sombra de regreso, de que toda clara visión se paga con algún tipo de ceguera parcial, de que toda ganancia va acompañada de alguna pérdida. ${ }^{56}$

De acuerdo con lo anterior es necesario decir que no se trata de renunciar a la experiencia revelatoria cristiana como plena y definitiva, pues quien ha vislumbrado a Cristo no puede dejarlo de lado; pero sí se debe entender que ello no excluye cuanto de verdadero y salvífico hay en las otras religiones. Tampoco se puede pretender adueñarse de Dios, de su dinamismo y de su gratuidad. La revelación de Cristo sigue mostrándonos a un Dios de todos y para todos. Por ello es importante saber que el cristianismo no misiona en medio del desierto, sino sale al encuentro de otros rostros del Señor manifestados en las religiones y culturas del mundo. ${ }^{57}$

Torres Queiruga ve un cambio de escenario que oscila peligrosamente entre el exclusivismo estrecho y el pluralismo indiferenciado. Todo ha cambiado en los últimos años: de visiones estrechas de la historia que se remontaba a unos seis mil años, se pasó a lo que nos presenta la paleontología, una historia humana que puede remontarse al millón de años; de una mundo reducido en el espacio a la zona mediterránea, se pasó a un mundo ancho de continentes habitados con culturas y religiones diversas; en fin, de un mundo donde el exclusivismo de Barth era comprensible, se pasó a un mundo donde el mismo parece incomprensible.

Por ello es entendible el paso al otro extremo, el universalismo indiferenciado de algunos, que termina quitando el sentido a todos. Fuera de lo anterior aparecen dos puntos álgidos: (1) la nueva concepción de verdad, que pasa de la verdad absoluta a la verdad como "consenso", del "objetivismo" al "consensualismo", y (2) la valoración de la historia influida por las religiones orientales, que aprecian la idéntica presencia vertical de lo Absoluto en cualquier momento del tiempo, del valor de la historia tensa

\footnotetext{
${ }^{56}$ Ibid., 391.

${ }^{57}$ Ibid., 391.
} 
entre el valor objetivo de la persona y la realidad de la maduración en tiempo. ${ }^{58}$ En el mundo globalizado, según lo anterior, es comprensible entonces la apertura hacia el universalismo indiferenciado.

Por lo demás, basta una ojeada realista a las religiones para ver que, por muchas distinciones que se hagan, las diversas propuestas no pueden reducirse a simples variaciones equipolentes: no solo presentan desniveles profundos que afectan a la experiencia misma, sino que implican muchas veces contradicciones insuperables. ${ }^{59}$

Según Torres Queiruga, el universalismo indiferenciado es impracticable por dos razones:

- La primera es el valor de la realización histórica o cierto nivel de objetividad que atribuimos a unas religiones y a otras no.

- La segunda es la historia interna de cada religión, que muestra un esfuerzo constante de purificación, crítica y progreso, y que no toda manera de vivir la religión es igualmente valida. "Por eso en cada momento toda religión reconoce la necesidad de una crítica que la haga más adecuada -o menos inadecuadaa la Realidad que intenta comprender, expresar y vivir." ${ }^{00}$

Pero si todas las religiones tienen algo de verdad, no todas pueden ser iguales. Aquí aparece el problema del criterio para realizar ese discernimiento.

La propuesta acogida por Torres Queiruga es la promoción de lo auténticamente humano. ${ }^{61} \mathrm{Y}$ este autor dice que lo humano es un concepto constitutivamente abierto ${ }^{62}$ al responder a las críticas formuladas contra el hecho de terminar haciendo depender la teología de las religiones de la antropología de cada época y contra la idea de que lo auténticamente humano pertenece a todas las religiones, sin definir a ninguna.

La única salida verdadera es la que constituye el riesgo y la gloria de todo lo humano: exponerse limpiamente a la oferta, esforzándose por reducir prejuicios teóricos o intereses egoístas, para intentar descubrir si y en qué medida una

\footnotetext{
${ }^{58}$ Ibid., 395-397.

${ }^{59}$ Ibid., 397.

${ }^{60}$ Ibid., 399.

${ }^{61}$ Este criterio ya había sido sugerido por otros autores, como dice el mismo Torres Queiruga, al citar a H. Küng y a C. Geffré (Torres Queiruga, Diálogo de las religiones y autocomprensión cristiana, 60-68).

${ }^{62}$ Idem, Repensar la revelación, 402.
} 
determinada oferta responde a la llamada auténtica del propio ser -de personaen-comunidad- y le abre posibilidades verdaderas y fecundas. ${ }^{63}$

En vista de lo anterior, Torres Queiruga ve necesario proponer nuevas categorías que permitan comprender mejor esta indiscutible pluralidad, buscando el diálogo y el verdadero encuentro.

En primer lugar propone la categoría "universalismo asimétrico": universalismo, porque su base es la convicción de que todas las religiones son, en sí mismas, caminos reales de salvación, y lo son porque expresan la presencia universal de Dios, quien quiere la salvación de todos (1Tm 2,4); asimétrico, porque lo anterior no significa que todas sean igualmente reveladoras, ya que -como se vio antes- existen diferencias reales entre ellas. ${ }^{64}$

El problema de la plenitud y definitividad del cristianismo se presenta así con toda su agudeza, pero cuenta también con las posibilidades del nuevo clima. Empezando porque nos hace ver que, de entrada, se trata de una pretensión enorme. Tan enorme, que solo resulta tolerable como confesión humilde y solidaria de quien cree haber descubierto algo que Dios quiere revelar y entregar a todos. Confesión que, por tanto, no debe silenciarse, pero sí esforzarse por aclarar su significado auténtico, eliminando toda pretensión de dominio y conquista. ${ }^{65}$

Aquí es necesario anotar cómo no deben ser entendidas la plenitud y la definitividad. La plenitud no puede entenderse como omnicomprensión porque, a fin de cuentas, la acogida humana será siempre frágil; tampoco puede entenderse como exclusión, pues en todas las religiones hay elementos alcanzados de verdad en distintos niveles; por su parte, la definitividad no puede entenderse como clausura, ya que es, más bien, la revelación plena pero dinámica. ${ }^{66}$

Torres Queiruga propone luego un "teocentrismo jesuánico":

...aquello sobre lo que, en definitiva, el cristiano apoya su convicción es la experiencia de Dios como $A b b a ́$, tal como brilló y sigue brillando a través de las palabras y obras, la vida, la muerte y la resurrección de Jesús. Esa es la gloria y la apuesta de la propuesta cristiana. ${ }^{67}$

\footnotetext{
${ }^{63}$ Ibid., 405-418; idem, Del terror de Isaac al Abbá de Jesús. Hacia una nueva imagen de Dios, 291-324; idem, Diálogo de las religiones y autocomprensión cristiana, 51-140. En las tres obras, Torres Queiruga trata las tres categorías que propone como inicio de solución al problema.

${ }^{64}$ Idem, Repensar la revelación, 406-407.

${ }^{65}$ Ibid., 408; idem, Diálogo de las religiones y autocomprensión cristiana, 51-97.

${ }^{66}$ Idem, 408-409.

${ }^{67}$ Ibid., 411.
} 
Con la expresión teocentrismo jesuánico parece más fácil hablar de Dios en cuanto misterio fundante, y a la vez, de la irrenunciable mediación en el Evangelio y en la persona de Jesús de Nazaret.

Por último, este autor propone "inreligionación”. Este es un neologismo nacido en relación con el término más conocido de inculturación. La inreligionación sería la aceptación de todo lo bueno de las religiones con las que se encuentra el cristiano y de los elementos valiosos que remiten a la común realidad divina, no para buscar la asimilación en una religión universal, sino para reafirmarse en el enriquecimiento que supone el diálogo con las otras religiones.

Hacia ahí apunta el significado de in-religionación: en el contacto entre las religiones: el movimiento espontáneo respecto de los elementos que le llegan desde otra ha de ser el de incorporarlos en el propio organismo, que de este modo no desaparece, sino que, por el contrario, crece. Crece desde la apertura al otro, pero hacia el misterio común. ${ }^{68}$

Ese misterio común sería el de Dios mediado en Jesucristo. Lo que habría de discutirse es ¿cómo se da esa mediación en las otras religiones? ¿Sé da en Cristo o por medio de otros mediadores? Esto debemos dejarlo como campo abierto para ulteriores análisis.

Con estas nuevas categorías, Torres Queiruga se propone dar paso a una propuesta desde la revelación que permita un verdadero diálogo interreligioso. Podemos entender así cómo la revelación es realmente clave para la teología de las religiones, pues es el fundamento de toda actuación teológica.

\section{Balance y perspectivas}

A modo de conclusiones queremos presentar este balance, junto con las perspectivas que se abren a nuestro interés.

La revelación es la donación de Dios que se da siempre y en todas partes, y ambos autores sostienen a su modo esta afirmación. Las implicaciones de una revelación así comprendida no son otras que la convergencia de la revelación y la salvación en un mismo accionar divino, pues las obras y palabras de Jesús son actuación histórica por medio de la cual Dios se revela y salva.

A la pregunta planteada al inicio de este artículo parece posible la respuesta de Torres Queiruga quien, al advertir que la revelación de Dios es tan generosa como su

${ }^{68}$ Ibid., 415. 
mismo amor, no puede encontrar limitaciones por parte Dios, pero sí las limitaciones del hombre, en este proceso revelatorio, pues es quien experimenta toda su finitud. "Podría pensarse una revelación que estuviera por encima de la finitud de tiempo y espacio, horizontes propios de la vida del ser humano, pero sería algo carente de sentido para él." ${ }^{69}$.

Para superar tal limitación, la revelación se da en y por la historia porque Dios no deja de donarse siempre y en todas partes. Tal autocomunicación histórica de Dios permite comprender lo que afirma Dupuis, de que toda historia es historia de salvación, pues Dios se autocomunica y salva asumiendo esa historia, y así garantiza la universalidad de la revelación.

Según lo anterior, es posible hablar de una revelación del Dios de Jesucristo en otras religiones, ya que Dios no dejará nunca de ofrecer gratuita y amorosamente su ser a los hombres. Podemos pensar -como lo dan a entender los autores que hemos presentado brevemente- que no es posible un verdadero diálogo interreligioso si no se da la posibilidad de la autocomunicación divina en la historia pues, a fin de cuentas, sería complejo un proceso semejante sin elementos que permitan compartir la propia experiencia de Dios desde la el contexto humano.

Surge una pregunta: ¿Se da en Cristo dicha revelación? La respuesta no es evidente. Ambos autores concuerdan con el magisterio en que la revelación en Cristo es plena y completa. ${ }^{70}$ Para Dupuis es insuperable, y aclara que la revelación se manifiesta en las otras religiones por medio del Espíritu, que sería, en definitiva, el que sirve de garante al destino divino de la humanidad. Para Torres Queiruga, la revelación en Jesucristo es plena y definitiva, por su carácter extraordinario, pero ello no impediría una revelación permanente de Dios para todos, es decir, una autocomunicación no excluyente.

Bien se puede afirmar que, tanto para Dupuis como para Torres Queiruga, la plenitud de la revelación en Cristo no obstaculiza la apertura autocomunicativa de Dios en otras religiones. Por ello, ambos autores, desde sus propias expresiones teológicas, señalan que la revelación no es excluyente ni exclusiva, pues el Dios que se autocomunica para salvarnos lo ha hecho y lo sigue haciendo de distintos modos para ofrecernos a todos su acción soteriológica.

\footnotetext{
${ }^{69}$ Sánchez Hernández, ¿Qué significa afirmar que Dios habla? Del acontecer de la revelación a la elaboración de la teología, 65.

${ }^{70}$ Congregación para la Doctrina de la Fe, Declaración Dominus Iesus 5.
} 
Nos parece importante insistir en que la definitiva e irrevocable revelación de Dios en Jesucristo no se relativiza por admitir, de alguna manera, la revelación divina en las otras tradiciones religiosas, pues si vemos en ellas elementos de verdad y de gracia -como decía el Vaticano II-, no podemos negar que esos elementos de la autocomunicación divina vienen de la verdad que es el mismo Dios.

Toda verdad depende de aquel que es la verdad y que la ha revelado al mundo en obras y palabras para nuestra salvación. Si despreciamos esos elementos de verdad y de gracia, como si no fueran acción divina en la historia humana, no pasarían de ser una especie de fugas al plan de Dios, como semillas caídas por equivocación en el campo de otras religiones.

Esta relación entre cristianismo y las otras religiones debe ser vista como una experiencia que nos hace capaces de descubrir, en las otras tradiciones religiosas, elementos que enriquezcan el conocimiento de Dios en el cristiano. Más aun, como dicen ambos autores, con sus respectivas explicaciones, las otras religiones son respetadas y vistas como enriquecedoras en el diálogo interreligioso. El hecho de una revelación abierta a todos los tiempos y todos los lugares no invita al hombre a un dominio por medio de la religión, sino a un verdadero diálogo constructivo en el cual todos ponen su propia experiencia de Dios que, a fin de cuentas, es valiosa y única.

Además, es indiscutiblemente justo que todas las religiones se consideren a sí mismas como verdaderas. Si no fuera así, nadie arriesgaría su vida por su confesión religiosa. Lo anterior no debe llevar a la confrontación o al colonialismo creyente, sino a caminar juntos en la búsqueda de ese Dios que nos quiere salvar.

Aparece aquí, en consecuencia, una nueva pregunta: ¿cómo debe ser entendída hoy la misión? A fin de cuentas, el encuentro dialogal no puede impedir a ninguno el anuncio de aquello en lo que cree. ${ }^{71}$ Además, si estamos convencidos de nuestra fe y la vivimos gozosamente, necesitaremos comunicarla, sin necesidad de imponerla a toda costa. Seguramente deberíamos seguir a Jesús, quien ofreció y ofrece su presencia salvadora a la libre elección del hombre. La misión como oferta de amor podría darse en el diálogo y por medio del testimonio; pero esto bien merece un análisis más profundo en la perspectiva de nuestros autores.

${ }^{71}$ Dupuis, "Dialogue and Proclamation: A Theological Commentary", 119-158; Idem. "Diálogo interreligioso en la misión evangelizadora de la Iglesia. Evolución de un concepto teológico en el margen de veinte años (1964-1984)”, 935-951; Congregación para la Evangelización de los Pueblos y Pontificio Consejo para el Dialogo Interreligioso, "Diálogo y anuncio", 1437-1454. 
En esta perspectiva de diálogo, no podemos olvidar lo dicho por Torres Queiruga: no todas las religiones son iguales, y por lo mismo sería necesario elegir un criterio para discernir la presencia de la revelación divina en ellas. Su propuesta sobre lo humano es discutida, y también ella queda abierta para el análisis, pues podría haber otros criterios más oportunos. Sin embargo, desde la propuesta de un Dios que se autocomunica en perspectiva de mayéutica histórica, no habría mejor criterio que lo verdaderamente humano para discernir los diversos grados o modos de revelación de Dios en las diversas confesiones religiosas.

Nuestro interés era ver la revelación como posible en las otras tradiciones religiosas y, más aún, como clave de la teología de las religiones. Creemos que será clave, para continuar el camino de la teología de las religiones, la posibilidad de comprender la revelación como experiencia abierta en la que el hombre, en su contexto, descubre su experiencia fundante, a la cual llega por ese "caer en la cuenta", descubriendo a Dios que se le manifiesta libre y amorosamente, para iluminarlo y salvarlo.

Quedan pues, muchos senderos por recorrer en este análisis creyente de la comprensión del pluralismo religioso como lugar teológico, y las dificultades del tema no pueden impedir la búsqueda sincera de una respuesta.

En esta perspectiva es necesario revisar la teología del diálogo interreligioso ${ }^{72}$, reconociéndolo como oportunidad y desafío. ${ }^{73}$ La Iglesia actual no puede dejar el diálogo como un imposible o como un simple encuentro de voluntades; es necesario que tome su lugar en el concierto de un mundo plural que quiere crecer y construirse más allá de la tolerancia.

\section{Bibliografía}

Concilio Vaticano II. "Constitución dogmática Dei Verbum sobre la divina revelación." En Documentos del Vaticano II. Constituciones, decretos, declaraciones, 157-180. Madrid: Biblioteca de Autores Cristianos, 1993.

- "Declaración Nostra aetate sobre las relaciones de la Iglesia con las religiones no cristianas." En Documentos del Vaticano II. Constituciones, decretos, declaraciones, 695-706. Madrid: Biblioteca de Autores Cristianos, 1993.

Conferencia Episcopal Española. "Notificación sobre algunas obras del prof. Andrés Torres Queiruga (29 de febrero de 2012).” Conferencia Episcopal Española, http://

\footnotetext{
${ }^{72}$ Francisco, Exhortación apostólica Evangelii gaudium 250-254.

${ }^{73}$ Dupuis, "Le dialogue interreligieux. Un défi et une chance", 14-19.
} 
www.conferenciaepiscopal.es/index.php/actividades-noticias-doctrina/2682notificaciones-sobre-algunas-obras-del-prof-andres-torres-queiruga.html (consultado el 2 de mayo de 2015).

Congregación para la Doctrina de la Fe. Declaración Dominus Iesus. Bogotá: Paulinas, 2000. [Acta Apostolicae Sedis, AAS, 92 (2000): 742-765].

- "Notificación a propósito de libro del Rvdo. P. Jaques Dupuis, S.J., Hacia una teologia cristiana del pluralismo religioso." Vatican, http://www.vatican.va/ roman_curia/congregations/cfaith/documents/rc_con_cfaith_doc_20010124_ dupuis_sp.html (consultado el 14 de abril de 2015). [Acta Apostolicae Sedis, $A A S, 94$ (2002): 141-145].

Congregación para la Evangelización de los Pueblos y Pontificio Consejo para el Dialogo Interreligioso. “Dialogo y anuncio.” Ecclesia 2547 (1991): 1437-1454 [Acta Apostolicae Sedis, AAS, 84 (1992): 414-446].

Dulles, Avery. El oficio de la teología. Barcelona: Herder, 2003. . Models of Revelation. Maryknoll (NY): Orbis Books, 1992.

Dupuis, Jacques. "Apostolic Exhortation Evangelii Nuntiandi of Pope Paul VI." Vidyajyoti 40.5 (1976): 218-230.

. "Dialogue and Proclamation: A Theological Commentary." In Redemption and Dialogue, editado por William R. Burrows, 119-158. Maryknoll (NY): Orbis Books, 1994.

. "Diálogo interreligioso en la misión evangelizadora de la Iglesia. Evolución de un concepto teológico en el margen de veinte años (1964-1984).” En Vaticano II. Balance y perspectivas. Veinticinco años después (1962-1987), editado por René Latourelle, 935-951. Salamanca: Sígueme, 1990.

. El cristianismo y las religiones. Del desencuentro al diálogo. Santander: Sal Terrae, 2002.

. Hacia una teología cristiana del pluralismo religioso. Santander: Sal Terrae, 2000. . Introducción a la cristología. Estella (Navarra): Verbo Divino, 1994. - Jesucristo al encuentro de las religiones. Madrid: Paulinas, 1991.

- "La teologia del pluralismo religioso revisitata." Rasegna di teología 40.5 (1999): 669-693.

- "Le débat christologique dans le contexte du pluralisme religieux." Nouvelle Revue Théologique 113 (1991): 853-863. 
. "Le dialogue interreligieux. Un défi et un chance." Choisir 538 (2004): 14-19. . "Le dialogue interreligieux a l'heure du pluralism." Nouvelle Revue Théologique 120 (1998): 544-563.

. "Le pluralism religieux dans le plan divin de salut." Revue thélogique de Louvain 29 (1998): 484-505.

. "Le Verbe de Dieu, Jesús Christ et les religions du monde." Nouvelle Revue Theologique 123 (2001): 529-546.

. "Méthode théologique et theologies locales." Seminarium 32 (1992): 61-74.

. "The Kingdom of God and World Religions." Vidyajyoti 51 (1987): 530-540.

. "The Truth Will Make You Free. The Theology of Religious Pluralism Revisited." Louvain Studies 24 (1999): 211-263.

. "World Religions in God's Salvific Design in John Paul II's Discourse to the Roman Curia." Seminarium 27 (1987): 29-41.

Francisco. Exhortación apostólica Evangelii gaudium. Ciudad del Vaticano: Librería Editrice Vaticana, 2013.

Geffré, Claude. Credere e interpretare. La svolta ermeneutica della teologia. Brescia: Editrice Queriniana, 2002.

Gibellini, Rosino. La teología del siglo XX. Santander: Sal Terrae, 1998.

Knitter, Paul F. Introducción a las teologias de las religiones. Estella (Navarra): Verbo Divino, 2007.

Meza, José Luis. "De la cristología a la cristofanía. Dupuis y Panikkar en diálogo.” Theológica Xaveriana 173 (2012): 115-136.

O'Collins, Gerald. “Jacques Dupuis. His person and Work." En In Many and Diverse Ways. In Honor of Jacques Dupuis, editado por Daniel Kendall y Gerald O’Collins, 18-29. Maryknoll (NY): Orbis Books, 2003.

. "Jacques Dupuis: The Ongoing Debate". Theological Studies 74 (2013): 632654.

Parra, Alberto. Textos, contextos y pretextos. Teología fundamental. Bogotá: Pontificia Universidad Javeriana, Facultad de Teología, 2003.

Pérez Prieto, Victorino. La búsqueda de la armonía en la diversidad. El diálogo ecuménico e interreligioso desde el Concilio Vaticano II. Estella (Navarra): Verbo Divino, 2014. 
Rahner, Karl. "Profane History and Salvation History." En Theological Investigations. (London: Darton, Longman and Todd, 1961-1992), XXI, 6: 4026-4033.

Sánchez Hernández, Olvani Fernando. ¿Qué significa afirmar que Dios habla? Del acontecer de la revelación a la elaboración de la teología. Bogotá: Universidad San Buenaventura, 2007. - "Inreligionación y pluralismo: una perspectiva teológica para el encuentro interreligioso." En Mirada pluridisciplinar al hecho religioso en Colombia: avances de investigación, Grupo Interdisciplinar de Estudios de Religión, Sociedad y Política, Giersp, 53-68. Bogotá: Universidad de San Buenaventura, 2008.

Teixeira, Faustino. Teología de las religiones. Una visión panorámica. Quito: Editorial Abya Yala, 2004.

Torres Queiruga, Andrés. "Aclaraciones sobre una notificación.” Concilium 346 (2012): 159-168.

. Del terror de Isaac al Abbá de Jesús. Hacia una nueva imagen de Dios. Estella (Navarra): Editorial Verbo Divino, 2000.

. Diálogo de las religiones y autocomprensión cristiana. Santander: Sal Terrae, 2005. . Fin del cristianismo premoderno. Retos hacia un nuevo horizonte. Santander: Sal Terrae, 2000.

- Repensar la revelación. La revelación divina en la realización humana. Madrid: Trotta, 2008. 